\title{
Toda a Memória do Mundo, parte um. Daniel Blaufuks
}

\author{
Daniela Zurita Herdoíza
}

\section{Resumen:}

El presente texto constituye una reflexión sobre la exposición Toda a Memória do Mundo, parte um del artista portugués Daniel Blaufuks. Esta crítica revisa algunos de los recursos usados por él para construir sus obras, las cuales usan imágenes o fotografías de archivo del campo de concentración nazi de la ciudad checa de Terezín. Este lugar fue el único visitado por la Cruz Roja Internacional en 1944, razón por la cual fue maquillado por los nazis para que pareciera un sitio pacífico, escondiendo así la dura realidad de estas prisiones.

El texto también explora los diferentes subtextos usados por Daniel Blaufuks en la construcción de sus obras artísticas; entre ellos se encuentran los relatos de W. G. Sebald y de Georges Perec, ambos sobre el Holocausto. Por último, se considera de qué manera la propuesta de Blaufuks puede ser disparadora de diferentes reflexiones relacionadas con varios contextos de características distintas.

Palabras claves: Exposición, obra artística, fotografías, memoria, campo de concentración, Holocausto.

\begin{abstract}
:
This article reviews Portuguese artist Daniel Blaufuks' exhibition “Toda a Memória do Mundo, parte um". This analysis explores some supplies the artist used to build his pieces, such as archival photographs and images of the Nazi concentration camp in the Czech city of Terezín. This was the only site visited by Red Cross International in 1944; therefore, it was embellished up by the Nazis so it could appear as a pacific place, hiding the harsh reality of these prisons. This article explores different subtexts used by Daniel Blaufuks in the making of his works, like the stories about the Holocaust written by W. G. Sebald and Georges Perec. Finally, the article looks into how Blaufuks' proposal triggers different notions regarding contexts with dissimilar characteristics.
\end{abstract}

Key words: exhibition, work of art, photographs, memory, concentration camp, Holocaust.

\section{Autora:}

Daniela Zurita (Ambato, 1984). Licenciada en Comunicación con Mención en Periodismo para Prensa, Radio y Televisión en la Pontificia Universidad Católica del Ecuador. En 2011 se especializó en el campo de Gestión Cultural dentro del programa académico de Estudios de Género y Cultura de la Facultad Latinoamericana de Ciencias Sociales. Actualmente es becaria de la SENESCYT y se encuentra cursando sus estudios en el programa de Maestría en Museología y Museografía en la Facultad de Bellas Artes de la Universidad de Lisboa en Portugal. 


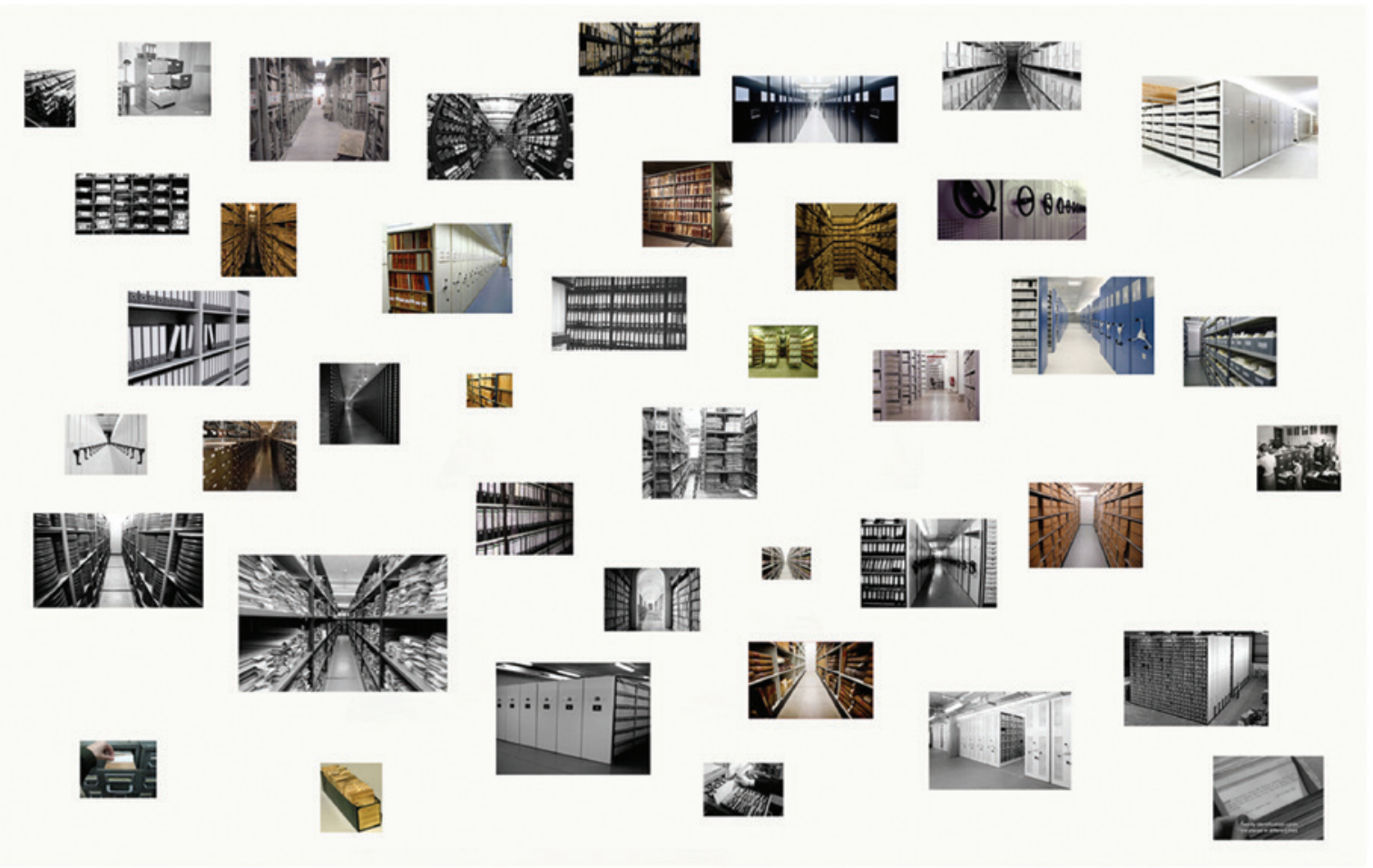

Fotografía 1. Fotografía del Panel de fotografías de la exposición Toda a Memória do Mundo, parte um, en MNAC, 2014. Fotografía de Blaufuks D,, (Lisboa, 2014) Cortesía del MNAR

Toda a Memória do Mundo, parte um es una de las exposiciones más recientes del artista visual portugués Daniel Blaufuks. A finales del año 2014, se llevó a cabo su inauguración en el Museo Nacional de Arte Contemporáneo de Lisboa (MNAC); contó con la curaduría de David Santos, director de la institución en ese momento.

Antes de empezar su carrera como artista, Blaufuks trabajó como fotógrafo de prensa, lo que más adelante le sirvió para su evolución a nivel estético. Su proceso creativo se intensificó a partir de 1996, cuando fue seleccionado como parte de los ocho finalistas para el Premio Europeo de Fotografía de ese año. En la actualidad, Daniel Blaufuks ha publicado más de 21 libros sobre su obra artística, ha realizado un gran número de exposiciones en ciudades como New
York, París, Madrid y Río de Janeiro; también ha incursionado en el campo audiovisual, en el cual ha desarrollado algunos proyectos en diferentes formatos.

El recurso de la memoria es recurrente en los trabajos de Blaufuks, en los cuales emplea imágenes de archivo en sus piezas; la exposición Toda a Memória do Mundo, parte um continúa con esta tendencia. Con las obras expuestas, en esta ocasión, el artista nos transporta a Terezín, ciudad checa donde estuvo instalado uno de los campos de concentración nazi que sirvió como sitio de tránsito para los judíos europeos, en su camino a Auschwitz. Cerca de 33000 personas encontraron la muerte en esta prisión debido a las nefastas condiciones de vida a las que se tuvieron que enfrentar. 
SÉRIE FOTO

\section{DANIEL BLAUFUKS}

\section{Toda a Memória do Mundo}

parte um

\section{All the Memory of the World}

part one

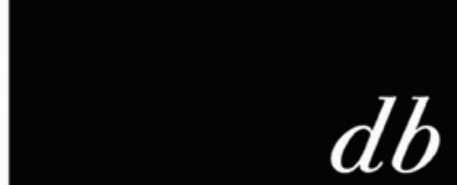

\section{W IN C K L ER}

Fotografía 2. Cubierta del libro Toda a Memória do Mundo, parte um, de Daniel Blaufuks. Fotografía de Blaufuks D., (Lisboa, 2014) Cortesía del MNAR

La particularidad de este lugar, que funcionó desde 1941 hasta 1945, radica en que fue el único visitado por la Cruz Roja Internacional, en 1944. Por esta razón, fue presentado como un sitio apacible con condiciones óptimas para una vida cotidiana tranquila y agradable. De esta forma se maquilló y escondió la verdad de los campos de concentración ante la mirada internacional de la época.

En el afán nazi por mostrar al mundo que los rumores sobre la persecución judía eran falsos, se filmó una película titulada El Führer da un pueblo a los judíos; en ella se mostraba la vida en Terezín después de los trabajos de embellecimiento. Estos consistieron en la construcción de fachadas falsas de tiendas y cafés, la adecuación de habitaciones confortables y bien decoradas, además de la creación de espacios para actividades deportivas y culturales. Después de terminado el rodaje de este filme, el equipo de producción y los actores fueron trasladados a Auschwitz, donde muchos de ellos murieron.

En su tiempo, muchas de las imágenes de Terezín sirvieron como propaganda nazi; ahora son vestigios materiales de la memoria y pertenecen al archivo histórico del Holocausto. Comprender el concepto de archivo resulta útil para aproximarse a la exposición Toda a Memória do Mundo, parte um, ya que juega en ella un papel muy importante. Entre las reflexiones pertinentes para este caso, tomo la de Michel Foucault, quien considera que el archivo es un 
sistema complejo imposible de comprender por completo; este surge en forma de fragmentos y en distintos niveles, por lo cual existe infinidad de conexiones y afirmaciones posibles que pueden hacerse sobre él. (Foucault, 1969)

Esta especie de fragmentación y multiplicidad de opciones que presenta el archivo es perceptible en las obras de Blaufuks. En su trabajo, el artista procura crear diferentes conexiones entre las imágenes de archivo; en sus palabras: "procurei seguir um percurso de formas diferenciadas de olhar, de variaçóes sobre a mesma temática, colecionando $e$ selecionando imagens de assuntos idênticos ou de palavras-chave similares e arranjandoas em formas visuais»'(Blaufuks, 2014). Lo que nos lleva a pensar que Blaufuks hizo su interpretación individual de los elementos de archivo que seleccionó, y concibió una obra que será dilucidada, a su vez, de múltiples formas por los espectadores.

La exposición Toda as Mémoria do Mundo, parte um está compuesta por tres espacios diferentes: una sala de video donde se usan fragmentos del filme de Terezín mencionado anteriormente, una biblioteca de consulta donde se encuentran algunas obras relacionadas con el tema propuesto por la exposición y, por último, el espacio donde se encuentran las obras.

En la primera sala, encontramos la fotografía de unos guantes blancos que aluden a la minuciosa investigación emprendida por el artista. Estos nos remiten a la misma acción de búsqueda dentro del archivo de la memoria. Una memoria empolvada, nublada pero siempre presente. Lo que sigue será el eslabón para la comprensión de la exposición; una mesa llena de libros de los que se sacaron las referencias para la creación

1 «Lograr un recorrido de formas diferentes de observar, de variaciones sobre la misma temática, coleccionando y seleccionando imágenes de asuntos idénticos o de palabras claves similares y ordenándolas en formas visuales». de este producto artístico. En este inmenso mar de información podemos encontrar dos obras literarias que constituyen influencias directas para el artista: la novela Austerlitz y la obra Wo el recuerdo de la infancia, además del propio libro de Blaufuks y otros ejemplares con información histórica de Terezín.

Una vez que hemos pasado el espacio introductorio, ingresamos a la sala de exposición donde apreciamos las obras ubicadas en las paredes. La distribución de las imágenes nos hace pensar que las páginas de un inmenso álbum fotográfico fueron desmontadas $y$ colocadas en las paredes de la exhibición. El trabajo de Blaufuks está compuesto por varios paneles de grandes dimensiones que contienen una inmensa cantidad de fotografías de archivo de procedencias diversas en cuanto a técnica y temporalidad. En la organización de todo este material, las imágenes se relacionan entre sí y forman verdaderas constelaciones o mapas visuales que construyen una narrativa; esta, aunque coherente, resulta difícil de comprender a primera vista.

Muchos de estos paneles están compuestos de forma que se enfatiza en un aspecto determinado; por ejemplo, uno de ellos está conformado por un gran número de fotografías de estaciones de tren europeas, muchas vacías, donde el silencio es el protagonista. Esta paz aparente, en el contexto de la exposición, en realidad remite el lugar donde, para muchos, empezaba el viaje a los campos de concentración, la posible muerte y el inevitable sufrimiento.

Por último, la exposición se completa con la exhibición de un video que dura cuatro horas. En él se muestran varias secuencias de archivo y otras escenas filmadas por el artista. La intención de este material es profundizar en la esencia de Terezín, cada rincón de la pequeña ciudad es mostrado con tomas en las que poco o nada 
sucede. Estas imágenes audiovisuales redundan sobre el tema del vacío, del abandono de un lugar que la humanidad quisiera olvidar. Sin embargo, Terezín está en el mapa, en el espacio del presente pero cargado de un pasado terrible y doloroso.

El video está compuesto de tal manera que sus escenas están bastante bien delimitadas, cada una de ellas tiene un principio y un final claramente definidos. El artista no espera que los visitantes observen el material en su totalidad pero sí que en minutos puedan percibir un poco de la memoria de Terezín.

La exposición Toda a Memória do Mundo, parte um necesita ser visitada con cierto conocimiento sobre el tema tratado por el artista. Antes de enfrentar las obras de Daniel Blaufuks tenemos que realizar un ejercicio intelectual complejo, de búsqueda e interpretación profunda, lo que, de todas formas, no nos asegura que podremos comprender su trabajo por completo. Los subtextos que Daniel Blaufuks evoca en este trabajo están relacionados no solo con la historia, sino también con las obras de dos escritores de culto de la literatura europea, quienes abordan el tema del Holocausto de formas diferentes. Me refiero al escritor alemán W. G. Sebald y su última novela Austerlitz (2001), y al escritor francés Georges Perec y su obra W o el recuerdo de la infancia (1975).

El libro de Sebald cuenta la historia de Jacques Austerlitz, un hombre solitario y enigmático, quien a partir de un retrato de su madre que, él cree, fue deportada a Terezín antes de ser enviada a su muerte en Auschwitz, emprende la búsqueda de su origen a través de imágenes del pasado y borrosos recuerdos de infancia (Sebald, 2004). En cuanto al relato de Perec, cuenta la propia historia del escritor como hijo de una pareja de judíos que mueren por causa de la guerra y cómo él consigue huir y esconderse con el resto de su familia durante esos duros años (Perec, 2014).

En estas historias, la ficción y la memoria se entremezclan de forma deliberada, se encuentra un gran número de citas que se cruzan entre ellas, lo que influye profundamente en la narración. Esto confunde a los lectores permitiéndoles, de manera inconsciente, incursionar en un proceso de exploración en la memoria de los personajes y narradores.

Estos dos autores forman parte de lo que Eva Hoffman llama hinge generation, la generación posmoderna, que es la que siguió a aquella que vivió los horrores de la Segunda Guerra Mundial. Las personas de esta generación también son conocidas como los Guardianes del Holocausto. Lo que sucede con estos hombres y mujeres es que, por lo general, hacen suyas las memorias y traumas de sus padres o de sus familiares más cercanos. (Hirsch, 2012)

En esta transmisión de memoria, la fotografía, debido a su carácter icónico y simbólico, jugó un papel muy importante, al ser el medio más poderoso que ligó a estas dos generaciones. El artista Daniel Blaufuks también utiliza la fotografía para conectarnos con el pasado, con las historias del Holocausto, como ya dije, bajo su propia interpretación.

Sin arriesgarme a decir mucho sobre todo el trabajo del artista y considerando que Daniel Blaufuks también proviene de una familia judía, lo que he podido concluir es que en su obra pone en práctica lo que Susan Sontag describió como «el dolor de los demás», una forma de contar las historias de los otros sin llamar la atención sobre nosotros mismos. (Sontag, 2003)

Así, después de haber leído las páginas del libro que acompaña a la exposición Toda a Memória do Mundo, parte um, me convencí que el trabajo de Daniel Blaufuks apela a muchos subtextos, 


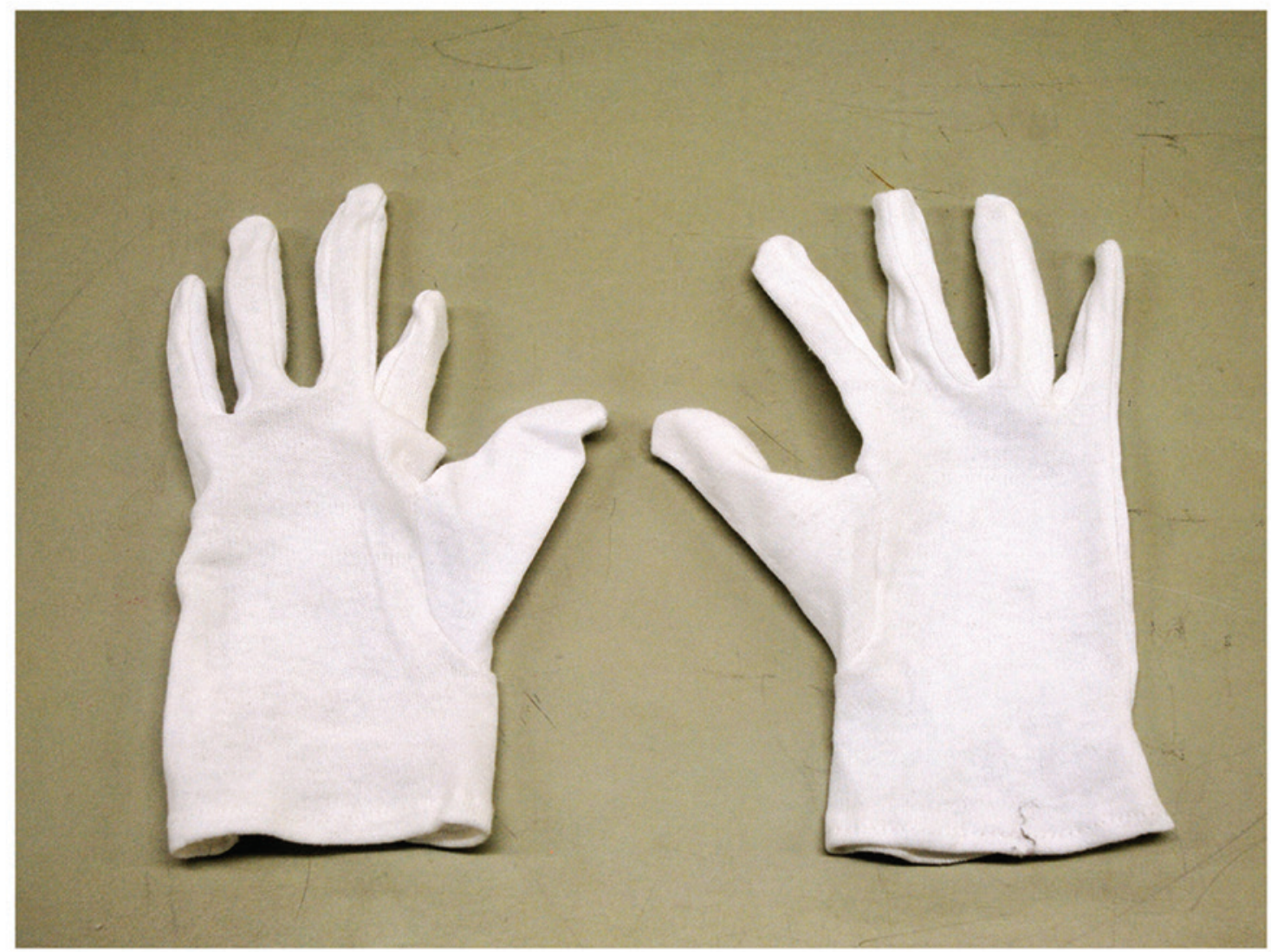

Fotografía 3. Fotografía de la exposición Toda a Memória do Mundo, parte um de la serie ITS, en MNAC, 2014 Fotografía de Blaufuks D., (Lisboa, 2014) Cortesía del MNAR

que es preciso conocer si queremos profundizar y navegar en la obra del artista. Si no hacemos esta tarea estaremos destinados a naufragar en el intento. $Y$ es que atrás de cada exposición de Daniel hay una labor inmensa de investigación, asociación e interpretación, sobre todo cuando trabaja con material de archivo. Como él mismo afirma, «sempre prefiro fazer um livro a uma exposição porque muitas vezes só se expóe parte do trabalho $»^{2}$ (Blaufuks, 2014)

Con base en esta declaración, se entiende que la exposición Toda a Memória do Mundo, parte um se presenta incompleta y esta es una de las razones por lo que es tan difícil de comprenderla. Para

2 «Siempre prefiero hacer un libro a una exposición, porque muchas veces solo se expone parte del trabajo». escribir este texto, me di a la tarea de profundizar en el trabajo que Daniel Blaufuks hace para esta exposición específica, y con seguridad puedo decir que descubrí muchos aspectos tan interesantes como vigentes. Conseguí acercarme más al tema del Holocausto, tan alejado de mi contexto sudamericano; sin embargo, hay una preocupación latente en mis reflexiones sobre esta muestra.

Yo hice la tarea, pero eso no quiere decir que todos los espectadores hayan realizado el mismo ejercicio, lo que habría sido una pena, sobre todo cuando había un discurso tan potente que podía ser un disparador de reflexiones diversas y aplicables a muchos contextos diferentes. Sin embargo, comprendo que lo que Blaufuks hizo 
fue crear en el museo un espacio para reflexionar, es decir, complicó la narrativa intencionalmente para retar al espectador. Esta propuesta se volvió compleja pero a la vez interesante en un mundo donde casi todo es entretenimiento de fácil consumo. Ahora que quedan pocos espacios para la reflexión; los museos tienen la tarea de estimular el pensamiento crítico a través de este tipo de obras al público.

El lado social y político de la obra de Blaufuks siempre está presente, aunque su intención no es ser reaccionaria o activista; sin embargo, de forma discreta y quizá inconsciente cumple con algunas de las características de lo que el filósofo francés Nicolas Bourriaud llamó estética relacional. Digo esto basándome en mi experiencia y por la manera que conseguí conectarme con la obra. El factor del espaciotiempo presentado en la exposición es realmente ajeno a mi contexto; a pesar de ello encontré vínculos con mi realidad y comparé historias y memorias, que podrían entenderse y criticarse con la misma dureza que el Holocausto.

Así, por ejemplo, reflexioné acerca de las dictaduras militares de los años 70 y 80 en Latinoamérica, en los millares de desaparecidos que todavía son recordados por sus familias, amigos y comunidades. También en los muchos asesinados en el conflicto armado colombiano que envuelve una lucha sin tregua entre gobierno, guerilla y paramilitares, disputa que ya tiene décadas de existencia y ninguna solución. Pero sobre todo, pensé en los 43 estudiantes normalistas desaparecidos y asesinados en Iguala, México, el 27 de septiembre de 2014, a manos de la policía municipal de la región.

A pesar de los horrores de la historia que nos antecede, todavía no hemos aprendido nada, el mundo continúa siendo un lugar inseguro.
Quizá de manera muy ingenua, me pregunto si la memoria está sirviendo de algo, si de verdad en algún momento puede transformarse en acción y resistencia.

Sé que todavía no he logrado percibir del todo la obra de Daniel Blaufuks, pero conseguí relacionar mis historias con aquella memoria trabajada por este artista. Cada espectador frente a este trabajo entrará en un diálogo con sus propias historias porque, a la final, eso es lo que nos construye como seres humanos en un mundo caótico y, a veces, incompresible.

\section{Bibliografía}

Blaufuks, D., (2014) Toda a Memória do Mundo, parte um. Lisboa: Ed. MNAR.

Bourriaud, N., (1998) Relational Aesthetics. Monts: Les presses du reel.

Foucault, M.,(1969) The Historical a priori and the archive (Seleccien del libro) The Archive I autor del libro Merewether Charles. London and Cambridge: White Capel and the MIT Press

Hirsch, M., (2012) The Generation of Postmemory. Writing and Visual Culture After the Holocaust. Nueva York: Columbia University Press

Perec, G., (2014) Wo El recuerdo de la infancia. Palencia: Ed. Menoscuarto

Saraiva, C., (2012) Arte y Comunidades. Um Arquivo Poético sobre o emvelhecimento. Lisboa: Ed. Faculdade de Belas Artes da Universidade de Lisboa

Sebald, W. G., (2004). Austerlitz. Barcelona: Ed Anagrama

Sontag, S., (2003) Regarding the Pain of Others. New York: Farrar, Strauss, and Giroux 


\section{Páginas web}

Monumento Nacional y Cultural. Praga, República Checa: Tipografía de la Memoria. Memorial de Terezín. Recuperado de http:// www.memoriales.net.

Bondy, R, (2001). Ghetto Terezin and its part in the Holocaust Givat Haim Ihub, Israel: Theresienstadt Martyrs Remembrance Association. Recuperado de http://www. bterezin.org.il

\section{Leyendas y créditos de las fotografías}

Fotografía \# 1

Leyenda: Fotografía del panel de fotografías de la exposición Toda a Memória do Mundo, parte um, en MNAC, 2014

Fotografía de Blaufuks D., (Lisboa, 2014) Cortesía del MNAR

Fotografía \#2

Leyenda: Cubierta del libro Toda a Memória do Mundo, parte um, de Daniel Blaufuks

Fotografía de Blaufuks D., (Lisboa, 2014) Cortesía del MNAR

Fotografía \#3

Leyenda: Fotografía de la exposición Toda a Memória do Mundo, parte um de la serie ITS, en MNAC, 2014

Fotografía de Blaufuks D., (Lisboa, 2014)

Cortesía del MNAR 